\title{
Developing Nursing Care Standards for Postoperative Gastrointestinal Patients
}

\author{
Elham Elhanafy ${ }^{1 *}$ Ishraga Mohamed $^{2}$ \\ 1. Assistant professor Nursing Administration Dep. Faculty of Nursing, Damanhour University, Egypt \\ Associate professor of Nursing Administration. Nursing College. Taibah University. K.S.A. \\ 2. Medical-Surgical Nursing Dep., College of Nursing. Taibah University, K.S.A \\ Assistant professor of Critical Care Nursing. Faculty of Nursing Sciences, Alnilain University. Sudan \\ *E-mail of the corresponding author: elham_youssef2006@yahoo.com
}

\begin{abstract}
Background: The postoperative arena is a unique environment that includes many challenging variables: complex clinical care performed by teams; high cost, sophisticated technologies that often do not interoperate; and a large array of supplies, instruments, and implants that are difficult to manage. Study aim: to develop a standard of nursing care for postoperative gastrointestinal patients. The study setting: was conducted at three postoperative gastrointestinal wards in the Gastro-Enterology Center at Mansoura University Hospitals. The subject: consisted of 90 juries, and 70 nurses working at the postoperative gastrointestinal care wards. The study tools: were two juries' opinionnaire and two observation checklists. The results: indicated that the observation checklist entailing nursing care for postoperative gastrointestinal patients was valid through full acceptance by juries. The checklist entailing structure items of postoperative gastrointestinal units was also validated by experts' consensus. Application of the checklist showed that the performance of bachelor nurses was higher than that diploma nurses. The reliability was tested through verifying internal consistency using the Cronbach's alpha coefficient and showed high reliability of the tool. All items of the initial checklist of nursing care for postoperative gastroenterology patients and an initial checklist of structure items were used in developing the nursing care standard for postoperative gastroenterology patients, which was also validated by experts. Conclusion and Recommendations: The developed standard for postoperative gastrointestinal patients is recommended to be applied at postoperative gastrointestinal units. Nurses working at postoperative gastrointestinal units should have a copy of the developed standards in Arabic and English languages.
\end{abstract}

Keywords: Nursing care standard, postoperative gastrointestinal

DOI: $10.7176 / \mathrm{JHMN} / 59-09$

\section{Introduction}

The postoperative arena is a unique environment that includes many challenging variables: complex clinical care performed by teams; high cost, sophisticated technologies that often do not interoperate; and a large array of supplies, instruments, and implants that are difficult to manage. These variables create an environment of massive complexity and, unfortunately, are a source of a significant percentage of patient safety-related adverse events (1). In addition to the outcome of patients who undergo gastrointestinal surgery varies greatly. Factors such as the patient's age and comorbidities, the complexity of the surgical procedure and the management of postoperative recovery influence the outcome (2).

The care strategy for patients' after gastrointestinal surgery had shifted tremendously over time. Also, the postoperative recovery period depends greatly on the availability and sufficiency of qualified nurses and physiotherapists. This dependency often represents a key bottleneck in postsurgical treatment, particularly in times of increasing economic demands. And again, close cooperation between the surgeon, anesthesiologist, and nurses are critical to the implementation of these elements $(2,3)$. In addition, nursing's contribution at the start, during and after the end of the surgery are clearly important, for example by certifying the client's identity and consent, the place, and the procedure; by verifying the vital signs and maintaining the patient monitored and with venous access; eliminating the presence of any risk, such as blood loss, airway difficulties, allergic reactions and postoperative complications; among other functions (4). So, nurses can support patients recovering from surgery and identify complications by applied standards for monitoring, assessment, and observation skills are essential in postoperative care (5). 
Professional standards describe the competent level of care in each phase of the nursing process. They reflect a desired and achievable level of performance against which a nurse's actual performance can be compared. The main purpose of professional standards is to direct and maintain the safe and clinically competent nursing practice. These standards are important to professional nurse because they promote and guide their clinical practice. They provide an evaluation tool to ensure clinical proficiency and safety. Professional nursing standards are also used to provide a framework for developing clinical competency checklists or proficiency evaluations for a specific clinical unit or employer (6).

The first who wrote about standards was Florence Nightingale. She introduced the first standards in nursing care, which resulted in a reduction of mortality rates in hospitals. In her book notes on nursing 1859, Nightingale illuminated the importance of good and safe care and highlighted the need to develop better standards in health care $(7,8)$. Also, the framework commonly used for establishing standards is Donabedian's framework model. It is composed of three entities; structure, process, and outcome (7). Moreover, standards are defined as written statements that define a level of performance; and are set of conditions determined to be acceptable by some authority. Standards are related to three major dimensions of quality care; structure, process, and outcome. Structure standards are related to the physical environment, organization, and management of the organization. Process standards are those connected with the actual delivery of care. Outcome standards involve the end of results of care that has been given $(7,9)$. Additionally, standards minimize the impact of potential disasters. Standards are specifications, which define materials, methods, processes or practices. Standards provide a basis for determining consistent and acceptable minimum levels of quality, performance, safety, and reliability. Standards are generally voluntary compliance documents and only become mandatory if called up in legislation or in contracts (10).

Development of standards of care for postoperative gastrointestinal patients is an essential step towards improving the quality of nursing care provided to these patients. Therefore, this study was conducted to guide nurses to carry out nursing care effectively, help them to improve their practice and achieve high-quality care. The study was intended to establish a basic standard of nursing care for gastrointestinal surgery based on the core competencies needed from nurses working in gastroenterology surgical units.

\subsection{The aim of the study}

To develop a standard of nursing care for postoperative gastrointestinal patients through:

1. Developing a checklist of nursing care entailing all criteria related to nursing care for postoperative gastrointestinal patients;

2. Testing the validity of the observation checklist from the experts' point of view;

3. Developing nursing standard; and

4. Testing the validity and reliability of nursing care standards.

\section{Subjects and methods}

\subsection{Study design:}

A cross-sectional operational research design was used.

\subsection{Setting:}

The study was conducted at three postoperative wards of gastrointestinal in the Gastroenterology Surgical Center at Mansoura University Hospitals. This center provides all types of GIT endoscopies and surgery, as well as liver surgery, and liver transplantation.

\subsection{Subjects:}

Two groups of subjects were included in the study, namely juries and staff nurses.

$\square$ Juries: to assess the content validity of the developed tool. They consisted of three categories: 30 nursing faculty members from the administration and medical-surgical nursing departments of the faculties of nursing at Damanhour and Mansoura universities. 30 medical faculty members from surgical and anesthesia departments of the faculty of Medicine at Mansoura University. In addition, 30 Head nurses representing 
nursing leaders in the field of service from the Gastroenterology Surgical Center, Emergency hospital, and Mansoura University Hospitals.

$\square$ Staff nurses: all available nurses in the study setting (70 nurses) with at least one-year experience in the current work position. They had either a diploma or baccalaureate degree in nursing.

\subsection{Tools of data collection:}

Five different types of tools were used for data collection, namely an opinionnaire for initial structure checklist, an opinionnaire for nurse' performance checklist, an observation checklist for nurse's performance, an observation checklist for unit structure, and an opinionnaire for validation of the developed standard.

Opinionnaire for the initial checklist: This opinionnaire sheet aimed at testing the validity of the initial checklist for structure items through juries' opinions. It covered structure items in the immediate postoperative gastrointestinal postoperative gastrointestinal wards. The opinions of the jury for each item was recorded on a dichotomous scale, whether agree or disagree, in addition to optional comments.

$\square$ Opinionnaire for nurse' performance checklist: This opinionnaire sheet aimed at testing the validity of the initial checklist of nursing performance through juries' opinions. It covered two main areas, namely general (overall opinion about the form or face validity), and nursing care for immediate postoperative gastrointestinal patients (process) in the immediate postoperative gastroenterology unit. The opinions of juries for each item was recorded on a dichotomous scale, whether agree or disagree, in addition to optional comments.

$\square$ Observation checklist for nurse' performance: This checklist was developed after reviewing different literature related to standards of nursing care for immediate post-operative gastrointestinal patients $(3,11$ 14). It aimed at assessing nurse's performance while providing immediate postoperative nursing care for gastroenterology patients. It was finalized based on juries' opinions for validation. It was divided into two parts:

Part I: covered nurse's personal data such as age, qualification, years of experience, and workplace.

Part II: developed for assessing the nursing care for immediate post-operative gastrointestinal patients through a list of 121 performance tasks covering various body systems as follows:

\begin{tabular}{ll}
\hline Area & No. of items \\
\hline Initial assessment & $\mathbf{9}$ \\
Nursing diagnosis & 4 \\
Nursing planning & 4 \\
Nursing interventions & 3 \\
Respiratory system & $\mathbf{1 2}$ \\
Circulatory system & 6 \\
Body fluid & 6 \\
Nausea and vomiting & 7 \\
Pain & 8 \\
Hypothermia & 6 \\
Incisions & 6 \\
Patient safety & 8 \\
Tubes and catheters & 19 \\
Prevention of infection & 7 \\
Patient anxiety & 4 \\
Physical mobility & 5 \\
Organization and communication of patient information & $\mathbf{4}$ \\
Evaluation & 3 \\
$\quad$ Total & 121 \\
\hline
\end{tabular}


- Observation checklist for structure: This checklist was developed after reviewing related literature for the structure of immediate post-operative gastrointestinal wards (2-4, 15-17). It was finalized based on juries' opinions for validation. It included 43 criteria as follows:

\begin{tabular}{ll}
\hline Area & No. of items \\
\hline Mission & 1 \\
Philosophy and objectives & 3 \\
Human and material resources & 13 \\
Health record-keeping system & 5 \\
Job description & 5 \\
Performance appraisal & 3 \\
Channels of communication & 2 \\
Patients environment & 8 \\
Physical and financial resources & 3 \\
$\quad$ Total & 43 \\
\hline
\end{tabular}

- Opinionnaire for standard: was developed for purpose of assessing the validity of the developed standards through juries' opinions. The opinions of juries for each item was recorded on a dichotomous scale, whether agree or disagree, in addition to optional comments.

\section{Pilot study:}

Was conducted aiming at evaluating the initial checklist clarity and relevance to the study objectives. It was conducted on a sample of ten juries, three physicians, four nursing faculty members, and three head nurses. These were not included in the main study sample.

\section{Fieldwork:}

Included two methods to collect the data needed for the development of the proposed nursing care standards for postoperative gastrointestinal patients. These were the validation of the constructed checklist and the filling out of the observation checklist for reliability testing. The duration of a collection of data for validity and reliability was four months, Jun 2018 - September 2018.

\section{Validity and reliability:}

Juries validated the initial checklist (process) entailing nursing care for postoperative gastrointestinal patients through full agreement. The initial checklist entailing structure items of postoperative gastrointestinal units was also validated by juries' consensus. The tool also showed a high degree of reliability through series measurements of nurses' performance. The internal consistency reliability analysis of the proposed observation checklist indicates that generally high Cronbach's alpha coefficients of reliability that ranged between 0.57 and 0.96 . The coefficient for the total performance measured by the checklist was as high as 0.96. Finally, the correlation coefficient for the total performance measured by the checklist was 0.59 for both intra- and inter-rater analyses.

\section{Standard development:}

Based on the validity and reliability results of the tool, the nursing care standard was developed. The researchers divided the proposed nursing care standard for immediate post-operative gastrointestinal patients according to Donabedian's model into three parts, namely process, structure, and outcome standards. The process standard entailed nursing care standard that should be rendered for an immediate postoperative gastrointestinal patient, followed by its criteria. Structure standard entailed structure items that should be available in the immediate postoperative gastrointestinal units. Then, the second opinionnaire sheets were developed for assessing the validity of the proposed standard. The sheet was redistributed to the same juries to express their opinions and comments on the proposed developed standards. 


\section{Administrative design:}

To carry out the study at the selected settings, official permission was obtained from the directors of the hospitals and the directors of nursing through a formal letter from the Faculty of Nursing at Damanhour University. Confidentiality of the obtained information was ensured.

\section{Statistical design:}

Data were presented using descriptive statistics in the form of frequencies and percentages for qualitative variables, and means and standard deviations for quantitative variables. Qualitative variables were compared using the chi-square test. Whenever the expected values in one or more of the cells in a $2 \times 2$ tables were less than 5 , Fisher exact test was used instead. In larger than $2 \times 2$ cross-tables, no test could be applied whenever the expected value in $10 \%$ or more of the cells was less than 5 . Pearson correlation analysis was used for assessment of the intra- and inter-rater reliability. Cronbach's alpha coefficient was calculated to assess the reliability of the developed tool through its internal consistency. Statistical significance was considered at p-value $<0.05$.

\section{Results:}

Table 1: Characteristics of jury groups in the study sample $(n=90)$

\begin{tabular}{|c|c|c|c|c|c|c|}
\hline & \multicolumn{6}{|c|}{ Jury groups } \\
\hline & \multicolumn{2}{|c|}{ Medical $(n=30)$} & \multicolumn{2}{|c|}{$\begin{array}{c}\text { Nursing Faculty } \\
(\mathrm{n}=30)\end{array}$} & \multicolumn{2}{|c|}{$\begin{array}{c}\text { Nursing Service } \\
(\mathrm{n}=30)\end{array}$} \\
\hline & No. & $\%$ & No. & $\%$ & No. & $\%$ \\
\hline \multicolumn{7}{|l|}{ Job position: } \\
\hline Lecturer & 24 & 80.0 & 23 & 76.7 & & \\
\hline Assistant professor & 4 & 13.3 & 7 & 23.3 & & \\
\hline Professor & 2 & 6.7 & & & & \\
\hline Nurse supervisor & & & & & 30 & 100.0 \\
\hline \multicolumn{7}{|l|}{ Specialty: } \\
\hline Surgery & 16 & 53.3 & & & & \\
\hline Anesthesia & 14 & 46.7 & & & & \\
\hline Medical-surgical nursing & & & 22 & 73.3 & & \\
\hline Nursing administration & & & 8 & 26.7 & & \\
\hline ICU & & & & & 14 & 46.7 \\
\hline Surgical ward & & & & & 16 & 53.3 \\
\hline \multicolumn{7}{|l|}{ Experience years: } \\
\hline$<15$ & 10 & 33.3 & 5 & 16.7 & 19 & 63.3 \\
\hline $15+$ & 20 & 66.7 & 25 & 83.3 & 11 & 36.7 \\
\hline Range & \multicolumn{2}{|c|}{$11.0-29.0$} & \multicolumn{2}{|c|}{$14.0-25.0$} & \multicolumn{2}{|c|}{$4.0-22.0$} \\
\hline Mean \pm SD & \multicolumn{2}{|c|}{$16.9 \pm 4.5$} & \multicolumn{2}{|c|}{$17.6 \pm 3.2$} & \multicolumn{2}{|c|}{$12.3 \pm 5.2$} \\
\hline
\end{tabular}

Table 1 describes the characteristics of the jury groups of the study. Most of the medical and nursing faculties were lecturers, $80.0 \%$ and $76.7 \%$, respectively. All those from service were nursing supervisors $(100.0 \%)$. As regards specialty, medical faculties were almost equally from surgery $(53.3 \%)$ and anesthesia (46.7\%). As for nursing faculty, they were mostly from medical-surgical specialty $(73.3 \%)$. Those in the nursing service were also almost equally distributed between surgery $(53.3 \%)$ and ICU $(46.7 \%)$. The mean experience years were highest for nursing faculty (17.6 \pm 3.2 years), and lowest for nursing service (12.3 \pm 5.2 years).

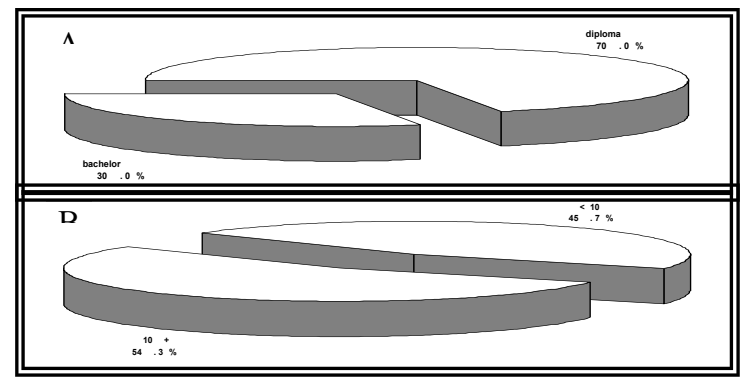

Figure 1: Nursing qualification (A) and experience years (B) in the study sample ( $n=70)$ 
Figure 1 describes the characteristics of the study nurses. It indicates that more than two thirds $(70.0 \%)$ were diploma nurses, and more than half $(54.3 \%)$ had ten or more experience years.

Part I. Validation of the developed observation checklist of nurses' performance through the opinions of jury groups

Table 2. Agreement of jury groups upon pre-operative assessment items of the proposed observation checklist of nurses' performance

1-Information concerning the preoperative condition and surgical/anesthetic details shall be transmitted to immediate postoperative hepatic patients nurse, such as:

- Current medical diagnosis

- Surgical procedure performed

- Known allergies

- Agents administered

- Complications during surgery

- Blood \& iv; fluid received an estimated blood loss

- Consent form

- Doctors' orders \& other investigations required

- Hematological \& radiological studies

- History of pathological factor such as hypertension, diabetes\& heart disease

\begin{tabular}{|c|c|c|c|c|c|c|c|}
\hline \multicolumn{6}{|c|}{ Jury groups } & \multirow{3}{*}{$X^{2}$} & \multirow{3}{*}{$\begin{array}{l}\mathrm{p}- \\
\text { value }\end{array}$} \\
\hline \multicolumn{2}{|c|}{$\begin{array}{l}\text { Medical } \\
(\mathrm{n}=30)\end{array}$} & \multicolumn{2}{|c|}{$\begin{array}{l}\text { Nursing } \\
\text { Faculty } \\
(\mathrm{n}=30)\end{array}$} & \multicolumn{2}{|c|}{$\begin{array}{l}\text { Nursing } \\
\text { Service } \\
(n=30)\end{array}$} & & \\
\hline No. & $\%$ & No. & $\%$ & No. & $\%$ & & \\
\hline 29 & 96.7 & 29 & 96.7 & 30 & 100.0 & 1.02 & 0.60 \\
\hline 27 & 90.0 & 28 & 93.3 & 30 & 100.0 & 2.96 & 0.23 \\
\hline 29 & 96.7 & 29 & 96.7 & 30 & 100.0 & 1.02 & 0.60 \\
\hline 30 & 100.0 & 30 & 100.0 & 30 & 100.0 & -- & -- \\
\hline 30 & 100.0 & 30 & 100.0 & 30 & 100.0 & -- & -- \\
\hline 30 & 100.0 & 30 & 100.0 & 30 & 100.0 & -- & -- \\
\hline 28 & 93.3 & 29 & 96.7 & 30 & 100.0 & 2.07 & 0.36 \\
\hline 29 & 96.7 & 29 & 96.7 & 30 & 100.0 & 1.02 & 0.60 \\
\hline 30 & 100.0 & 30 & 100.0 & 30 & 100.0 & -- & -- \\
\hline 30 & 100.0 & 30 & 100.0 & 30 & 100.0 & -- & -- \\
\hline
\end{tabular}

(--) Test results not valid

The agreement of jury groups upon preoperative assessment items of the proposed observation checklist of nurses' performance is presented in table 2. It is noticed that all of the service group members $(100.0 \%)$ have agreed upon all the items. As for the other two groups, the percentages of agreement ranged between $90.0 \%$ for the surgical 
procedure performed and $100.0 \%$. However, no statistically significant differences could be revealed among the three groups.

Part II: Observation of the performance of nurses using the developed observation checklist

Table 3: Pre-operative assessment items of the proposed observation checklist of nurses' performance as observed among study nurses

\begin{tabular}{|c|c|c|c|c|c|c|}
\hline \multirow{3}{*}{$\begin{array}{l}\text { Information concerning the preoperative condition and } \\
\text { surgical lanesthetic course shall be transmitted to immediate } \\
\text { postoperative gastrointestinal patients nurse, such as: }\end{array}$} & \multicolumn{4}{|c|}{ Nursing qualification } & \multirow{3}{*}{$\mathrm{X}^{2}$} & \multirow{3}{*}{$\begin{array}{l}\mathrm{p}- \\
\text { value }\end{array}$} \\
\hline & \multicolumn{2}{|c|}{$\begin{array}{l}\text { Diploma } \\
(\mathrm{n}=49)\end{array}$} & \multicolumn{2}{|c|}{$\begin{array}{l}\text { Bachelor } \\
(\mathrm{n}=21)\end{array}$} & & \\
\hline & No. & $\%$ & No. & $\%$ & & \\
\hline & 45 & 91.8 & 21 & 100.0 & Fisher & 0.31 \\
\hline - $\quad$ Surgical procedure performed & 45 & 91.8 & 18 & 85.7 & Fisher & 0.42 \\
\hline & 44 & 89.8 & 20 & 95.2 & Fisher & 0.66 \\
\hline - $\quad$ Agents administered & 37 & 75.5 & 13 & 61.9 & 1.33 & 0.25 \\
\hline Complications during surgery & 35 & 71.4 & 14 & 66.7 & 0.16 & 0.69 \\
\hline $\begin{array}{l}\text { - Blood \& iv; fluid received an } \\
\text { estimated blood loss }\end{array}$ & 38 & 77.6 & 14 & 66.7 & 0.91 & 0.34 \\
\hline & 41 & 83.7 & 12 & 57.1 & 5.63 & $0.02 *$ \\
\hline $\begin{array}{l}\text { Doctors' orders \& other } \\
\text { investigations required }\end{array}$ & 49 & 100.0 & 21 & 100.0 & 0.00 & 1.00 \\
\hline $\begin{array}{l}\text { - Hematological \& radiological } \\
\text { studies }\end{array}$ & 47 & 95.9 & 18 & 85.7 & Fisher & 0.16 \\
\hline $\begin{array}{l}\text { - History of pathological factor } \\
\text { such as hypertension, diabetes\& } \\
\text { heart disease }\end{array}$ & 46 & 93.9 & 21 & 100.0 & Fisher & 0.55 \\
\hline
\end{tabular}

(*) Statistically significant at $p<0.05$

Table 2 illustrates the performance of preoperative assessment items of the proposed observation checklist of nurses' performance as observed among study nurses. Only one item was performed by all nurses, diploma, and bachelor, which was that of transmitting doctor's orders and other investigations required (100.0\%). Conversely, only $57.1 \%$ of bachelor nurses have performed the item of the consent form, compared to $83.7 \%$ of diploma nurses, and the difference was statistically significant $(\mathrm{p}=0.02)$. 
Part III. Reliability of the developed observation checklist

Table 4. Correlation of performance of rater 1 test-re-test (intra-rater reliability) and rater 1 and rater 2 performance (inter-rater reliability)

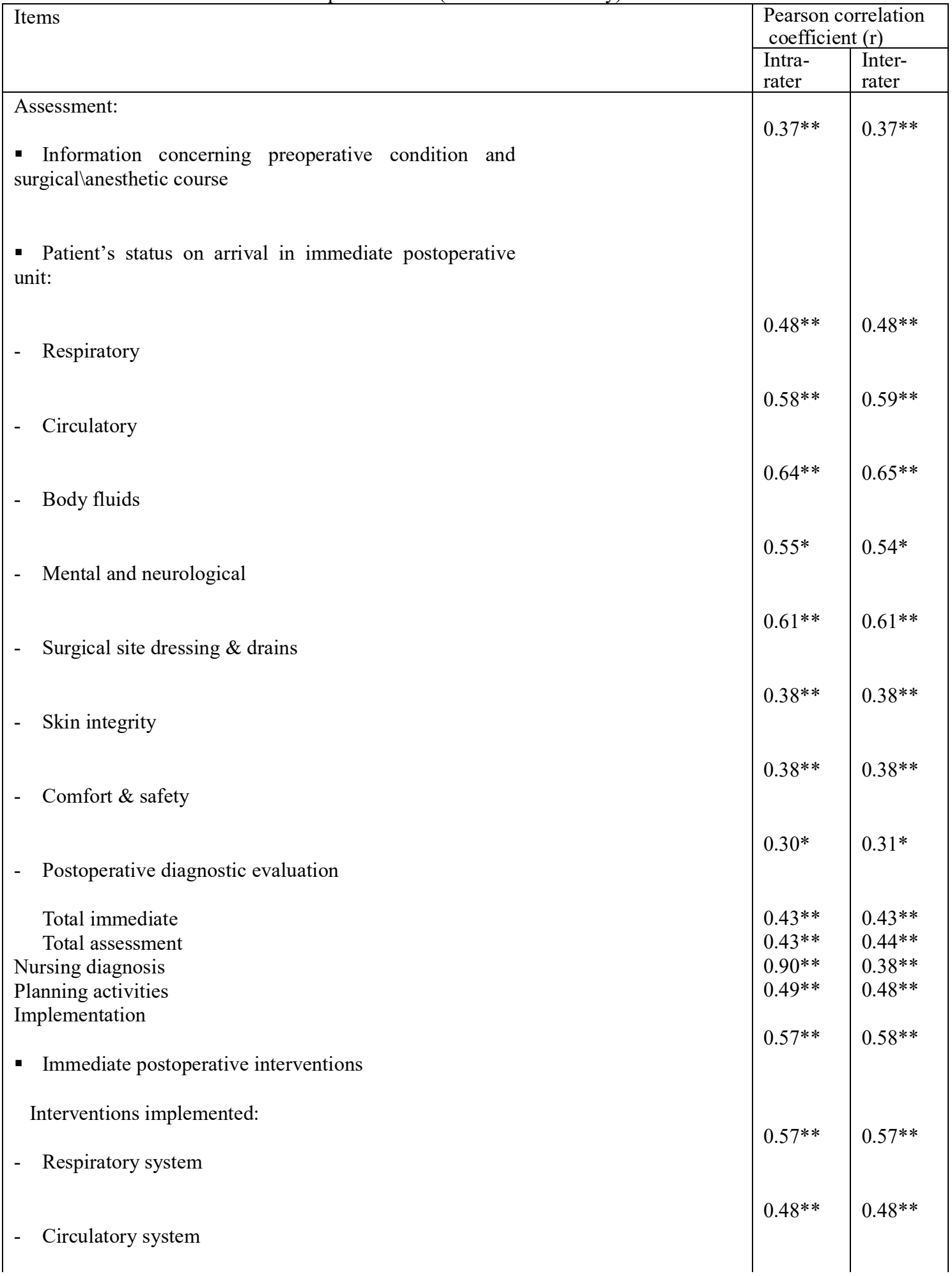




ISE

- Body fluids

- Nausea and vomiting

- Postoperative pain

- Hypothermia

\begin{tabular}{|c|c|}
\hline $0.26^{*}$ & $0.26^{*}$ \\
\hline $0.55 * *$ & $0.56^{* *}$ \\
\hline $0.60 * *$ & $0.60 * *$ \\
\hline $0.53 * *$ & $0.54 * *$ \\
\hline 0.21 & 0.21 \\
\hline $0.52 * *$ & $0.52 * *$ \\
\hline $0.67 * *$ & $0.68 * *$ \\
\hline $0.43 * *$ & $0.43^{* *}$ \\
\hline $0.54 * *$ & $0.54 * *$ \\
\hline $0.61 * *$ & $0.62 * *$ \\
\hline $0.62 * *$ & $0.61 * *$ \\
\hline $0.51 * *$ & $0.52 * *$ \\
\hline $0.47 * *$ & $0.48 * *$ \\
\hline $0.56^{* *}$ & $0.56^{* *}$ \\
\hline $0.59 * *$ & $0.59 * *$ \\
\hline $0.27 * *$ & $0.28 * *$ \\
\hline $0.55 * *$ & $0.55^{* *}$ \\
\hline $0.59 * *$ & $0.59 * *$ \\
\hline
\end{tabular}

- Tubes and catheters care:

Nasogastric tube

T- tube

Drains

Urinary catheter

Total tubes care

- Prevent infection

- Relieve anxiety

- Improve physical mobility

Total implementation

Organization and communication of patient information

Evaluation

Total performance

$0.59 * *$

$0.59 * *$

(*) Statistically significant at $p<0.05 \quad$ (**) statistically significant at $p<0.01$

Table 4 illustrates the results of the test-retest reliability analysis of the proposed observation checklist are illustrated. It points to statistically significant intra-rater correlations, which ranged between 0.21 and 0.90 , and inter-rater correlations, which ranged between 0.21 and 0.68 . Only one item had no statistically significant correlation in both intra- and inter-rater analyses, which was related to interventions implemented to the incision. The correlation coefficient for the total performance measured by the checklist was 0.59 for both intra- and interrater analyses.

Table 5. Cronbach's alpha coefficient (internal consistency) of performance observation checklist

\begin{tabular}{|l|l|}
\hline & $\begin{array}{l}\text { Cronbach's alpha } \\
\text { coefficient }\end{array}$ \\
\hline Assessment: & 0.57 \\
$\begin{array}{l}\text { Information concerning the } \\
\text { preoperative condition and } \\
\text { surgicallanesthetic course }\end{array}$ & 0.84 \\
$\quad \begin{array}{l}\text { Total immediate } \\
\text { Nursing diagnosis }\end{array}$ & 0.92
\end{tabular}




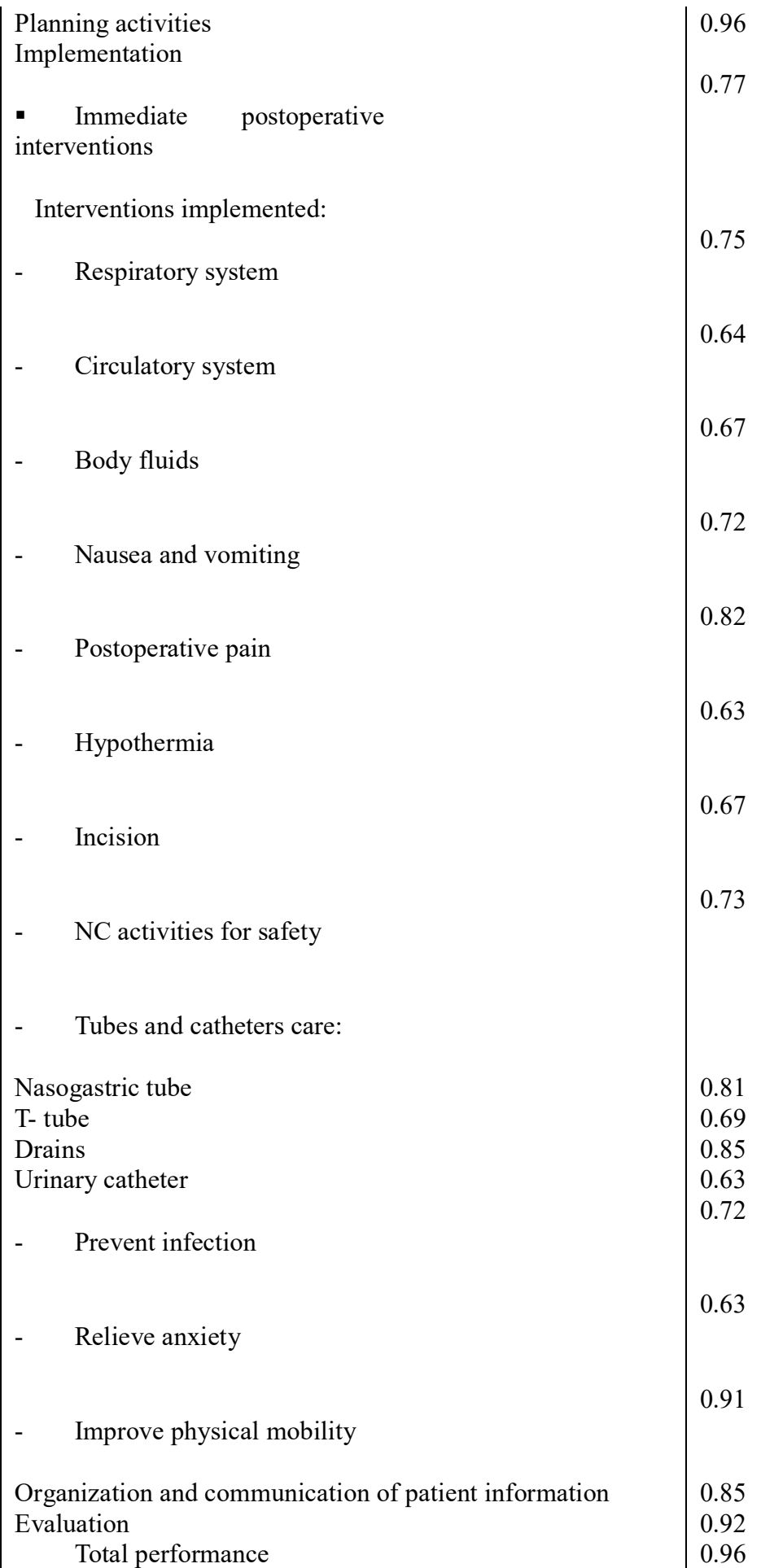

Table 5 presents the results of the internal consistency reliability analysis of the proposed observation checklist. It indicates generally high Cronbach alpha coefficients of reliability that ranged between 0.57 and 0.96 . The coefficient for the total performance measured by the checklist was as high as 0.96 . 
Part IV. Structural inventory of study setting and total structure and process

Table 6. Structural inventory of the three Units under study

\begin{tabular}{|l|l|l|l|}
\hline Items & Ward 1 & ward 2 & ward 3 \\
\hline 1-Mission: & 100.0 & 100.0 & 100.0 \\
\hline 2- Philosophy: & 0.0 & 0.0 & 0.0 \\
\hline 3-Objectives: & 100.0 & 100.0 & 100.0 \\
\hline 4-Human and material resources: & 100.0 & 100.0 & 100.0 \\
\hline 5- Health record-keeping system & 100.0 & 100.0 & 100.0 \\
\hline 6- Job description: & 100.0 & 100.0 & 100.0 \\
\hline 7- Performance appraisal: & 100.0 & 100.0 & 100.0 \\
\hline 8- Channels of communication: & 100.0 & 100.0 & 100.0 \\
\hline 9- Patient environment: & 100.0 & 100.0 & 100.0 \\
\hline 10- Physical and financial resources: & 100.0 & 100.0 & 100.0 \\
\hline
\end{tabular}

Table 6 illustrates the results of the inventory of structural items in the three study settings. It shows that all items were fulfilled in all three settings. The only exceptions were related to the philosophy, which was neither written nor available for all staff members.

Table 7: Overall adequacy of structure and performance of process nursing care standards as observed among study nurses $(\mathrm{n}=70)$

\begin{tabular}{|c|l|l|}
\hline \multirow{2}{*}{} & \multicolumn{2}{|l|}{ Done/present } \\
\cline { 2 - 3 } & No. & $\%$ \\
\hline Total: & & \\
Structure $(\mathrm{n}=3)$ & 3 & 100.0 \\
Process $(\mathrm{n}=70)$ & 70 & 100.0 \\
\hline
\end{tabular}

Table 7 shows that overall, all study settings had suitable adequate structure, and all the nurses had an adequate level of performance of nursing care standards.

Table 7 presents the agreement of the jury groups upon the developed standard. It points to a total agreement $(100.0 \%)$ upon all aspects of the standard

\section{Discussion}

As regards the validity of the checklist of the nursing care for immediate postoperative gastrointestinal patients, the majority of the juries in the present study have agreed upon all items of the proposed preoperative nursing assessment items. These findings are consistent with the findings of (18) who have reported that the nursing preoperative assessment can be useful in identifying and defining patients' risk factors and vulnerabilities not just for surgery, but for the entire perioperative care trajectory. Communication of patient risk factors and vulnerabilities to the entire perioperative team is critical for a successful transition through the perioperative environment to occur. If patients' vulnerabilities or risks cannot be lessened, they need to at least be identified so they can be managed as they shift within the complexity of the perioperative environment.

The lowest percentage of agreement was related to the consent form, and this was among medical juries. This is congruent with (19) who reported that inform consent should be integrated into our surgical practice. Unfortunately, a big gap exists between the theoretical/legal best practice and the daily practice of inform consent. An optimally informed patient will have more realistic expectations regarding a surgical procedure and its associated risks. Wellinformed patients will be more satisfied and file fewer legal claims. The use of interactive computer-based programs provides opportunities to improve the SIC process. Kamer, et al (20) stated that we believe in the regulation of informed consent by sub-specialization associations under the flag of Turkish Surgical Association is a very important matter and will standardize informed consents, and this will be as beneficial for physicians as the patients and also will protect the physicians in probable trials. In addition, Borello (21) findings showed that Simplified surgical consent documents meet the goals of health literacy and informed consent. Educational level appears to be a strong predictor of understanding. 
Part VI. Validation of the developed standard

Table 8. Agreement of the jury groups upon developed standard $(n=90)$

\begin{tabular}{|c|c|c|}
\hline \multirow{2}{*}{ Items } & \multicolumn{2}{|c|}{ Agree } \\
\hline & No. & $\%$ \\
\hline - The statement looks like a standard & 90 & 100 \\
\hline - The proposed standard statement wrote: & & \\
\hline - Clear & 90 & 100 \\
\hline - Correct & 90 & 100 \\
\hline - Scientific & 90 & 100 \\
\hline - Appropriate & 90 & 100 \\
\hline - The proposed standard covers all section. & 90 & 100 \\
\hline - The standard statements are understandable. & 90 & 100 \\
\hline - The standard criteria are measurable. & 90 & 100 \\
\hline - Criteria are related to the title of the standard. & 90 & 100 \\
\hline - The standard is free from any redundant items. & 90 & 100 \\
\hline - The form is free from any duplication. & 90 & 100 \\
\hline - There is a balance among various sections of the form. & 90 & 100 \\
\hline - There is a logical sequence of the various sections. & 90 & 100 \\
\hline $\begin{array}{l}\text { - The standard reflects the specialized care required to the } \\
\text { immediate postoperative hepatic patients. }\end{array}$ & 90 & 100 \\
\hline $\begin{array}{l}\text { - The proposed standard can be used to guide nurses in the } \\
\text { immediate postoperative hepatic unit }\end{array}$ & 90 & 100 \\
\hline $\begin{array}{l}\text { - The proposed standard can be used in evaluating the task } \\
\text { performed by nurses in the immediate postoperative hepatic unit. }\end{array}$ & 90 & 100 \\
\hline
\end{tabular}

Observation of the present study nurses during carrying out patient care showed that only slightly more than half of them have performed the items of the consent form. This might be because the consent form might be considered as a routine paper to be signed without a need to explain to the patient all the procedures and side effects of any intervention, and the physician may delegate this to the nurse to complete the consent form and obtain patient's signature. The previous results are inconsistent with Sherlock, and Brownie, (22), who found that patients' recollection and understanding of the medical procedure, risks and complications are often low, particularly among older individuals. The use of interactive multimedia and written material that are easy to read and comprehend, and prepared for individual patients has been shown to increase patient awareness, recollection, and understanding of the consenting procedure.

Regarding item related to planning, the majority of the current study juries agreed upon all proposed items. This finding is in congruence with Scand, (15) who emphasized that the value of structures in nursing records and care plans is proven by its support of daily workflow, delivery of nursing care and data reuse. This facilitates continuity of care, thus contributing to patient safety. Nurses need more education and managerial support in order to be able to benefit from structures in nursing records and care plans, also, Castellan, (23) argued that the analysis of nursing diagnoses, outcomes and interventions confirmed an intense activity in response to a broad spectrum of patient needs. The number of nursing diagnoses allowed predicting patient outcomes. The analysis of nursing diagnosis frequencies may help to estimate the patients' complexity and the need for nursing interventions and can predict hospital outcomes. 
Implementation is the actual performance of the nursing interventions identified in the care plan. As far as nursing intervention is concerned, the great majority of the present study juries agreed upon all items. The importance of this step has been highlighted by Paans, (8) who stated that the Effective documentation systems that support nurses in linking diagnoses, interventions, progress, and outcome evaluations could be helpful. In this regard, Agyeman, and Korsah, (24) reported that registered nurses are taught the nursing process, and they are expected to implement the acquired knowledge in the clinical area. The failure of nurses to practice the expected standard of care results in their relying on the decision of other health-care professionals, such as doctors, therefore, it is suggested that nurses must show evidence of using the nursing process in their daily work by the use of the nursing care-plan form.

Concerning the validation of the material resources items for the immediate postoperative gastrointestinal patient wards, all the juries in the present study agreed upon all the proposed items. This is in agreement with Klaiber, et al. (25) who mentioned that a good postoperative outcome in patients undergoing major visceral surgery without superiority of preoperative patient education compared to standard patient care at a high-volume center. However, preoperative patient education is a helpful instrument not only for teaching patients but also for training the nursing staff.

Concerning the validation of the checklist entailing structure items, all juries in the present study agreed upon the importance Performance appraisal: , This is similar to Waheed, et al (26) who reported that when employees perceive quality in performance appraisals, they tend to be more innovative at work by adopting new skills, techniques, and practices. In order to stimulate innovative behavior from employees, managers should empower their employees and one way of doing so is to enhance their perceptions regarding the quality of performance appraisals.

The findings of the present study showed that all the juries agreed upon the importance of the job description items. This is in congruence with Krishnam, and Sweta (27) who illustrated that the majority of the respondents agree that unclear job description led to the poor performance of an employee so there is a need to developed proper job description for each employee with the specific qualification that is required for specific job and position to avoid employees ${ }^{\text {ee }}$ poor performance.

Upon the agreement of the jury groups regarding, the development of a standard. It points to total agreement $(100.0 \%)$ upon all aspects of the standard, this finding emphasized the importance of the developing and validating the standard, (28) who developed a nursing practice guideline for pre and postoperative care of gastric cancer patients, further stressed that this will improve the quality of clinical nursing and the expertise of nurses.

\section{Conclusion:}

Based on the findings of the present study, it was concluded that the studied postoperative gastrointestinal wards had no standard for nursing care of postoperative gastrointestinal patients, and there was a need for such standard in the wards. The checklist entailing nursing care for postoperative gastrointestinal patients was valid through full acceptance by juries. The checklist entailing structure items of postoperative gastrointestinal units were also validated by juries' consensus. The checklist showed that the performance of bachelor nurses was higher than, the diploma nurses. The reliability was ascertained through estimating internal consistency (Cranach's alpha coefficient), which proved to be high. All items of the initial checklist of nursing care for postoperative gastrointestinal patients an initial checklist of structure items were used in developed a nursing care standard. A standard for postoperative gastrointestinal patients was proposed and validated by juries.

\section{Recommendations:}

- The developed standard for postoperative gastrointestinal patients is recommended to be applied at postoperative gastroenterology units.

- Nurses working at postoperative gastrointestinal units should have a copy of the developed standards in Arabic and English languages.

- Quality improvement programs and quality assurance mechanisms must be established in the study center for evaluating and improving the quality of care provided. 
- Planning for continuing education courses should be held to keep nurses up-to-date in their knowledge and performance.

\section{References}

1- Paul J. Jacques, and Michael N. Minear (2008) Improving Perioperative Patient Safety Through the Use of Information Technology. Advances in Patient Safety: New Directions and Alternative Approaches (Vol. 4: Technology and Medication Safety).

2- $\quad$ Marian Grade, Michael Quintel \& B. Michael Ghadimi (2011).Standard perioperative management in gastrointestinal surgery. Langenbecks. 396:591-606. DOI 10.1007/s00423-011-0782-y

3- Joseph C. Carmichael, Deborah S. Keller, Gabriele Baldini, et al. (2017). Clinical Practice Guidelines for Enhanced Recovery after Colon and Rectal Surgery from the American Society of Colon and Rectal Surgeons and the Society of American Gastrointestinal and Endoscopic Surgeons. Diseases of the colon \& rectum Vol. 60 : 8 the American Society of Colon \& Rectal Surgeons, Inc.

4- Grigoleto ARL, Gimenes FRE, Avelar MCQ. Segurança does clients e as ações Frente ao procedendo cirúrgico. (2011) Rev. Eletr. Enf. 13(2). Disponivel: http://dx.doi.org/10.5216/ree.v13i2.10326 .SGNA.

5- $\quad$ Nursing Times, Postoperative care 1 (2013): principles of monitoring postoperative patients.

6- Charlotte Davis (2014). The importance of professional standards. Nursing made Incredibly Easy! September/October. Lippincott Williams \& Wilkins.

7- $\quad$ American Nurses Association, (2010). Scope and standards of practice. Silver Spring, Md.

8- Paans, W et al (2010), Prevalence of accurate nursing documentation in patient records. Journal of Advanced Nursing, 66: 2481-2489. doi:10.1111/j.1365-2648.2010.05433.x

9- $\quad$ Eleanor J Sullivan; Phillip J Decker (2009). Effective leadership and management in nursing. Upper Saddle River, N.J.: Pearson Prentice Hall, Penn Nursing Science. (2012). History of Nursing Timeline. Retrieved from www.nursing.upenn.edu/nhhc/Pages/timeline_1900-1929. aspx?slider1=1\#chrome.

10- $\quad$ Standards New Zealand, 2008

11- Society of Gastroenterology Nurses and Associates (SGNA) (2014). Standards of Clinical Nursing Practice and Role Delineations.

12- Patton, Dana; Gupta, Neera, Wojcicki, e al. (2010). Postoperative Outcome of Colectomy for Pediatric Patients with Ulcerative Colitis. JPGN. Volume 51. https://journals.lww.com/jpgn/pages/default.aspx

13- Denise M. Jackson, Ellice M. Mellinger, Barbara A. Ricker, Linda P. Voyles et al. (2015). Standards of perioperative nursing. AORN.

14- $\quad$ ORNAC Operating Room Nurses Association of Canada. $13^{\text {th }}$ ed. (2017) ORNAC standards, guidelines, and position statements for perioperative registered nurses. Published by ORNAC in the pub. April, 469 pages

15- Scand J. (2014).Impacts of structuring nursing records: a systematic review. Caring Sci.28; $629-647$.

16- Malley, Ann et al (2015): "The role of the nurse and the preoperative assessment in patient transitions" AORN journal vol. 102,2 (2015): 181.e1-9.

17- Charlotte Davis (2014). The importance of professional standards. Nursing made Incredibly Easy! September/October. Lippincott Williams \& Wilkins.

18- Malley, Ann et al (2015): "The role of the nurse and the preoperative assessment in patient transitions" AORN journal vol. 102,2 (2015): 181.e1-9.

19- Leclercq WK, et al (2010). A review of surgical informed consent: past, present, and future. A quest to help patients make better decisions. 34(7):1406-15. doi: 10.1007/s00268-010-0542-0. Review.PMID:20372902.

20- Kamer, E., et al (2018). Importance of informed consent defined by General Surgery Associations in Turkey. Turkish journal of surgery, 34(2), 97-100. doi:10.5152/turkjsurg.2018.3755

21- Borello, Alessandro et al (2016). "Use of a simplified consent form to facilitate patient understanding of informed consent for laparoscopic cholecystectomy" Open medicine (Warsaw, Poland) vol. 11,1 564-573. 16 Dec. 2016, doi:10.1515/med-2016-0092

22- $\quad$ Sherlock, A. and Brownie, S. (2014), Informed consent: a literature review. ANZ J Surg, 84: 207-210. doi:10.1111/ans.12555

23- Castellan C et al (2016) Nursing diagnoses, outcomes, and interventions as measures of patient complexity and nursing care requirement in Intensive Care Unit. Journal of Advanced Nursing 72(6), $1273-1286$. doi: $10.1111 /$ jan.12913.

24- Agyeman-Yeboah, J., \& Korsah, K. A. (2018). Non-application of the nursing process at a hospital in Accra, Ghana: lessons from descriptive research. BMC Nursing, 17, 45. doi:10.1186/s12912-018-0315-x.

25- Klaiber, U., et al. (2018). Impact of preoperative patient education on the prevention of postoperative complications after major visceral surgery: the cluster randomized controlled PRODUCT trial. Trials, 19(1), 288. doi:10.1186/s13063-018-2676-6 
26- Waheed, A., et al (2018). 'Perceptions of Performance Appraisal Quality' and Employee Innovative Behavior: Do Psychological Empowerment and 'Perceptions of HRM System Strength' Matter?. Behavioral sciences (Basel, Switzerland), 8(12), 114. doi:10.3390/bs8120114

27- Dr. K. Krishnam Raju, Dr. Sweta Banerjee (2017) "A Study on Job Description and its Effect on Employee Performance: Case of Some Selected Manufacturing Organizations in the City of Pune, International Journal of Latest Technology in Engineering, Management \& Applied Science (IJLTEMAS)Volume VI, Issue II, February 2017 | ISSN 2278-2540

28- Park MO, Park HA. (2010). Development of a Nursing Practice Guideline for Pre and Post-Operative Care of Gastric Cancer Patients. Healthc Inform Res. Dec; 16(4):215223. https://doi.org/10.4258/hir.2010.16.4.215. 